\title{
Repair of coarctation of the aorta, bicuspid aortic valve, subaortic membrane and ascending aotic aneurysm in a single session
}

\author{
Ertan Demirdaş ${ }^{1}, K_{\text {Ivanç Atılgan }}^{1}$, Oğuz Taşdemir ${ }^{2}$
}

1) Bozok University Research and Application Hospital and Cardiovascular Surgery, Assist. Prof., Yozgat, Turkey

${ }^{2)}$ Medicana International Hospital, Cardiovascular Surgery, Prof. Dr., Ankara, Turkey

\begin{abstract}
$10 \%$ of the coarctation of the aorta (COA) cases are diagnosed higher than 40 -year of age and other cardiac pathologies accompany to $40 \%$ of these cases. The cause of mortality in $20 \%$ of undiagonised cases is the aortic rupture of ascending aorta. Aneurysm of the ascending aorta (AAA), COA, bicuspid aortic valve (BAV)and subaortic membrane were observed in a young male patient referring to our medical center with dispnea. The patient was operated and all pathologies were repaired in one single session. AAA or aortic dissections (AD) accompanying with other cardiac pathologies like BAV, ventricular septal defect (VSD) can be repaired in one single operation by an accurate surgical approach.
\end{abstract}

Keywords: Fungal endocarditis, myxoma, aspergillus 


\section{Introduction}

Coarctation of the aorta (COA) is characterized by narrowing in the descending aorta distal to the left subclavian artery. It is very common and almost accounts for $5-7 \%$ of congenital heart diseases. Nearly $85 \%$ of patients with COA have a bicuspid aortic valve (BAV). ${ }^{(1)}$ Most of the patients having COA remain asymptomatic until adulthood and are diagnosed mostly on investigation for systemic hypertension. $10 \%$ of COA cases are diagnosed higher than 40 -year of age and other cardiac pathologies accompany to $40 \%$ of these cases. ${ }^{(2,3)}$ The cause of mortality in $20 \%$ of undiagonised COA cases is the aortic rupture of ascending aorta, and in $75 \%$ of instances, rupture occurred in the ascending aorta. ${ }^{(4)} \mathrm{Al}$ though the association between COA and aneurysm of the ascending aorta (AAA) or aortic dissections (AD) has been wellknown, surgical treatment of accompanying pathologies of the ascending aorta in patients with COA have been uncommon.

Figure 1

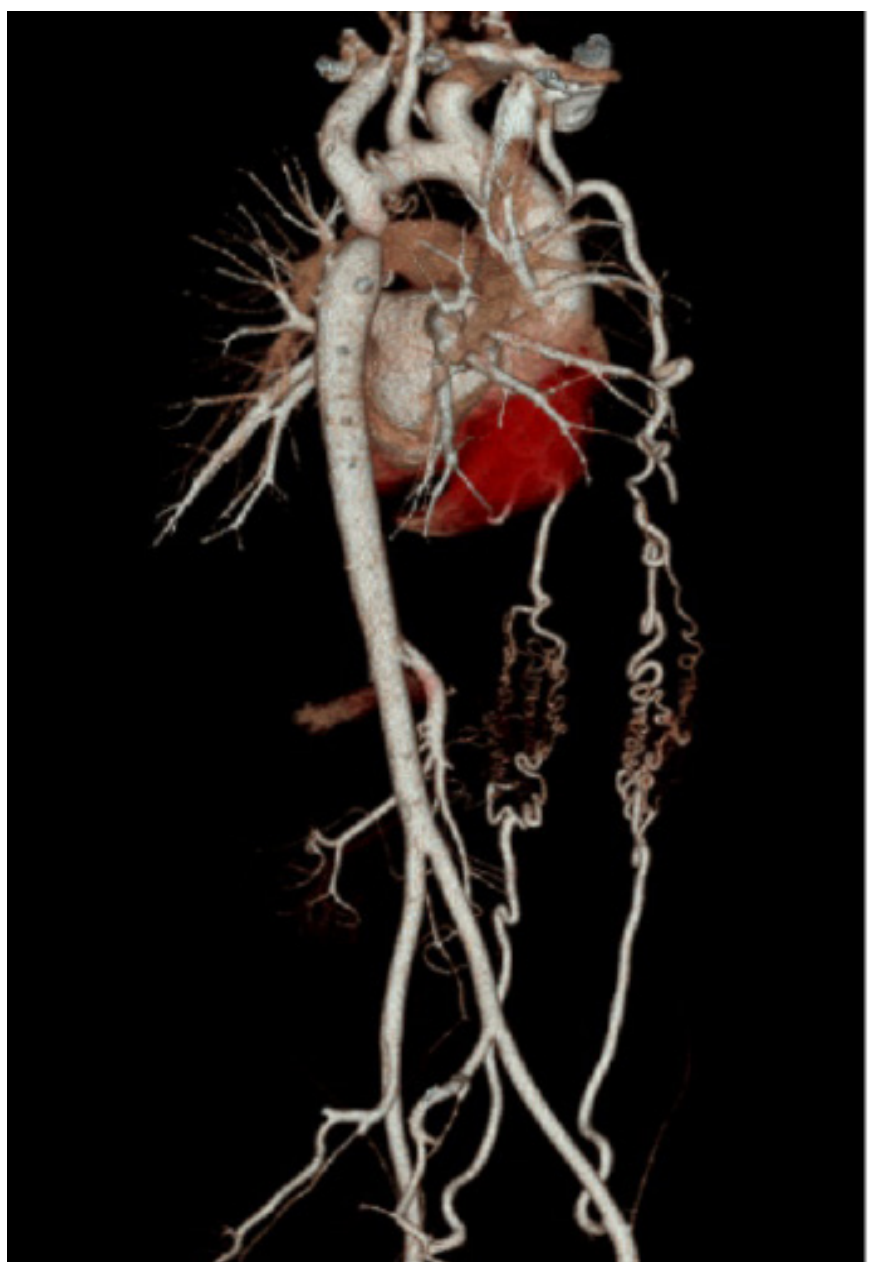

\section{Case History}

A 19-year old male patient was referred to our clinic with a dispnea. On the physical examination $1 / 4$ aortic diastolic murmur was auscultated. Bilateral lower extremity pulses were non-palpable. Tension arterial was 147/80 $\mathrm{mmHg}$. On transthoracic echocardiography (TTE) ejection fraction was $62 \%$, minimaly aortic insufficiency, BAV, subaortic membrane were observed and left ventricule output tract gradient was $41 / 18 \mathrm{mmHg}$. Aortic root diameter was $36 \mathrm{~mm}$ and ascending aorta diameter was $53 \mathrm{~mm}$ in TTE. A computerized tomographic angiography (CTA) was planned and aortic root diameter was 38 $\mathrm{mm}$, ascending aorta diameter was $55 \mathrm{~mm}$, arcus aorta diameter was $24 \mathrm{~mm}$ and distal part was $16 \mathrm{~mm}$ and a coarctation was observed just after the left subclavian artery origin on CTA (Figure 1,2). The patient was operated and all pathologies were repaired in one single operation. A control CTA was applied and the patient was discharged on the postoperative sixth day (Figure 6).

Figure 2

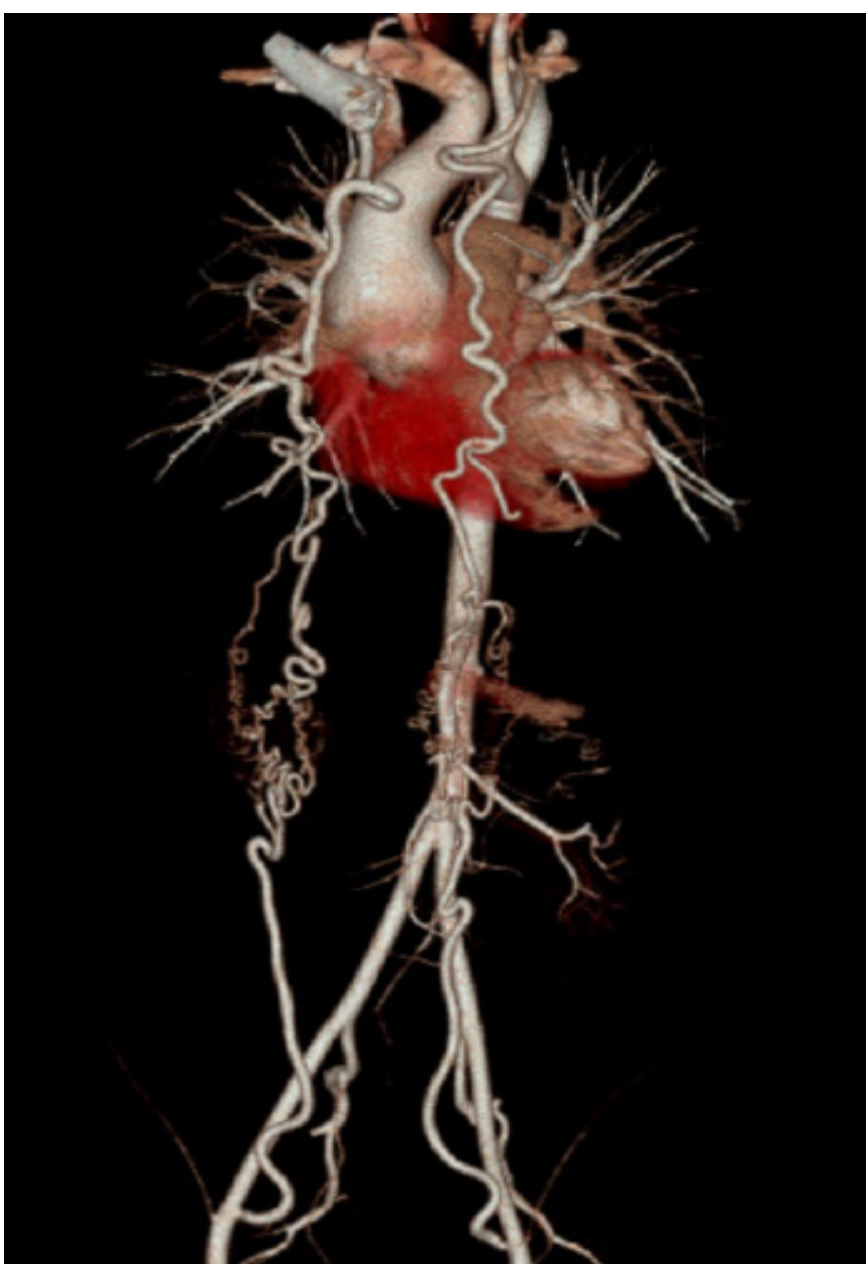




\section{Operating Procedure}

Right axillary artery and right common femoral ven were cannulated. After median sternotomy, the patient was cooled to $26 \mathrm{oC}$. The ascending aorta was aneurysmatic (Figure 3). Cardiac arrest was obtained after antegrade and retrograde cold crystalloid cardioplegia. The aorta was clamped on the distal part of the aneurysm and after aortotomy bicuspid arotic valve, subaortic membrane and aneurysmatic aorta was resected. Coronary ostiums were prepared in button shape and Benthall procedure was applied with a $25 \mathrm{~mm}$ mechanic prosthetic aortic valve (SJM Regent ${ }^{\mathrm{TM}}$ Mechanical Valve) and 30 $\mathrm{mm}$ Dacron graft. Spontaneous beat after warm blood cardioplegia and declamping was observed. The proxi-

\section{Figure 3}

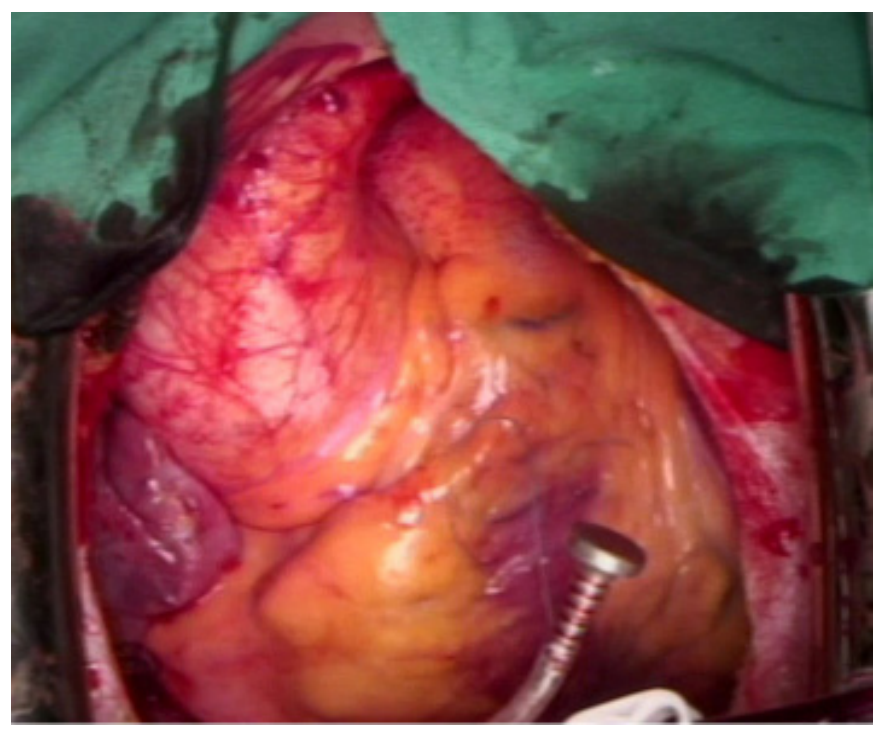

Figure 5

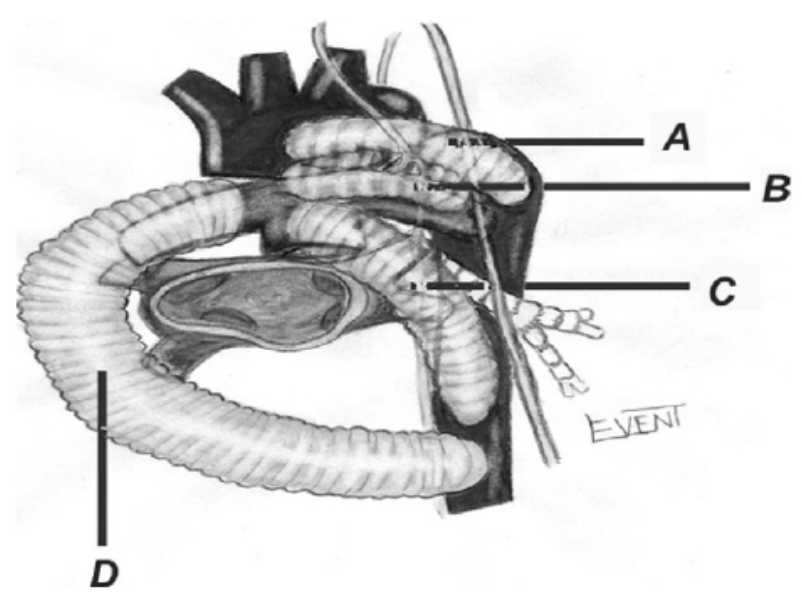

mal part of a $14 \mathrm{~mm}$ Dacron graft was anastomosed to the ascending aorta graft and then the graft was passed under the left pulmonary hilus and left side of the heart and anastomosed to the distal of the coarctation (Figure $4,5 c)$. Total aortic x-clamp time was 160 minutes and total cardiopulmonary bypass time was 227 minutes.

\section{Discussion}

Ascending aorta and aortic valve diseases are mostly associated with COA. The main point in the pathology of COA should be the developmental abnormality of neural crest tissue causing medial degeneration and aortic dilatation. The systemic hypertension originating from $\mathrm{COA}$ ends up with the gradual weakening of the arterial wall and may cause AAA or AD.

Figure 4

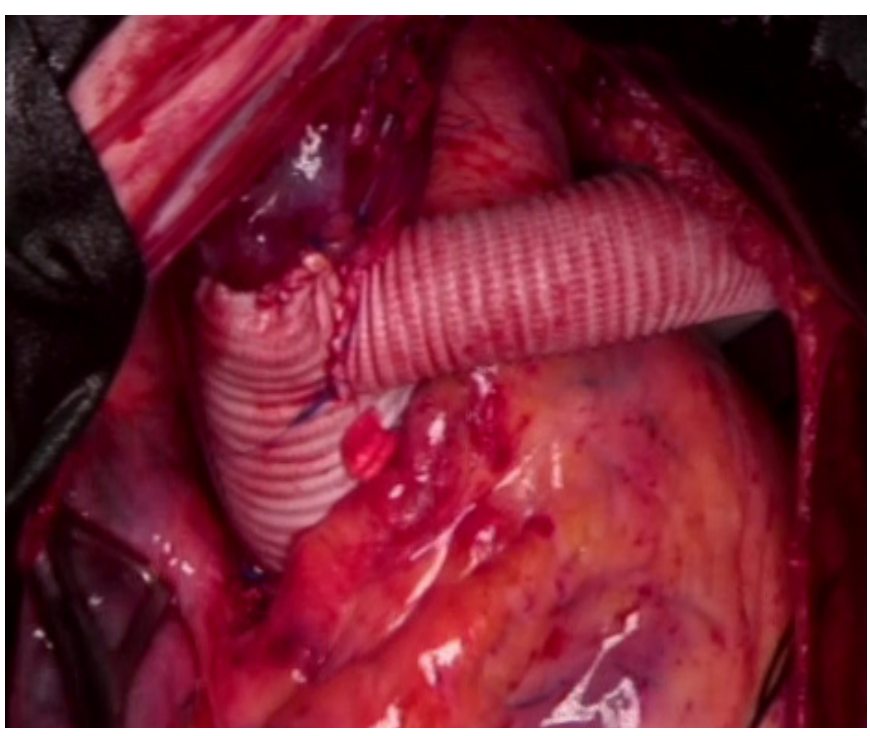

Figure 6

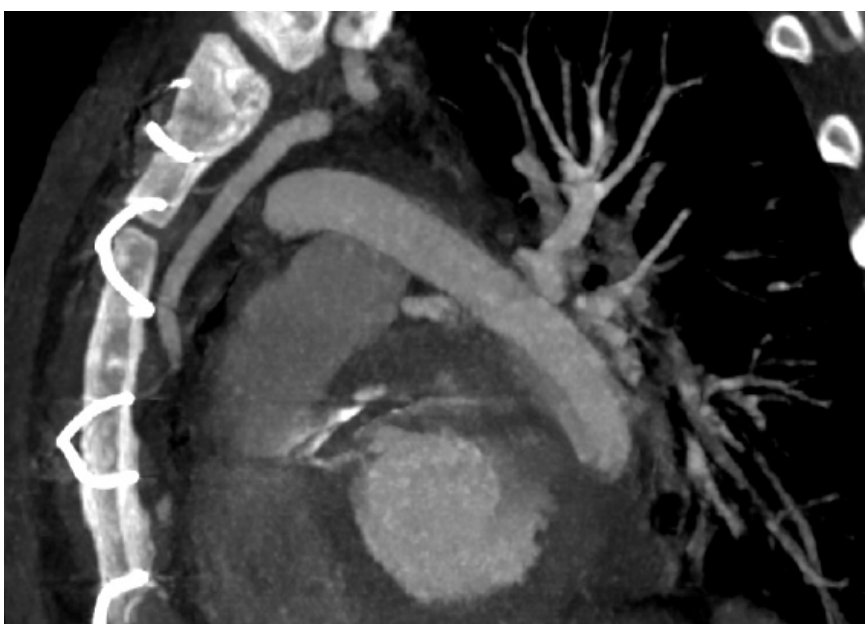


Surgical treatment of accompanying pathologies of the ascending aorta in patients with COA have been uncommon. Lawson et al described the first successfull repair of $\mathrm{COA}$ and chronic $\mathrm{AD}$ association, which was managed with a two stage operation. In the first stage COA was repaired in order to reduce the proximal hypertension and prevent the progression of the $\mathrm{AD}$, since ascending aorta replacement without the repair of COA may cause congestive heart failure and perioperative bleeding through the suture lines due to high afterload pressure. On the other hand, the increased afterload might be the cause of bleeding and haemodynamic instability in patients whose cardiac lesions are operated in the first stage.

After cross-clamping due to the increase of afterload and wall strain, atrial fibrillation and ischaemia might occur in the dilated ventricle. Also, in the distal segment of the coarctation, ischaemia might be seen due to the low cardiac output. Thus, the repair of COA and AAA or
$\mathrm{AD}$ in one single operation may have better results.

Another important point in the repair of COA is the extraanatomic bypass procedure. The first extraanatomic bypass was described by Siderys et al in 1974 . They bypassed ascending aorta and the distal of the renal artery of the descending aorta by using a $22 \mathrm{~mm}$ Dacron graft. ${ }^{(5)}$ Figure 5 shows the four main procedures of the repair of COA. ${ }^{(6)}$ Using a side-clamp for the proximal and distal anastomoses of the graft for the extra-anatomic correction of coarctation prevents paraplegia, allowing the blood flow to the branches of the aorta and the intercostal arteries. ${ }^{(2)}$

In this case, we prefered to place Dacron graft above the phrenic nerve through the lateral pericardium and paid attention to avoid vagal and phrenic nerve injuries. As a result; the repair of COA accompanying with cardiac pathologies like AAA or AD, BAV, ventricular septal defects in one single operation can be managed safely.

\section{References}

1. Motamed ZK, Garcia J, Kadem L. Fluid Dynamics of Coarctation of the Aorta and Effect of Bicuspid Aortic Valve. PLoS One. 2013; 8(8): e72394.

2. Sabol F, Mistrikova L, Kolesar A, Luczy J, Toporcer T, Beres A. Onestage surgical approach to coarctation of the aorta and ascending aortic aneurysm. Bratisl Lek Listy 2014; 115(9);593-6.

3. Cokkinos DV, Leachman RD, Cooley DA: Increased mortality rate from coronary artery disease following operation for coarctation of the aorta at a late age. J Thorac Cardiovasc Surg 1979, 77:315-8.
4. Abbott ME: Coarctation of the aorta of the adult type. Am Heart J 1928, 3:574-618.

5. Siderys H, Graffs R, Hallbrook H, et al. A technique for management of inaccessible coarctation of the aorta. J Thorac Cardiovasc Surg 1974;67:568-70.,

6. Ugur M, Alp I, Arslan G, Temizkan V, Ucak A, Yilmaz AT. Four different strategies for repair of aortic coarctation accompanied by cardiac lesions. Interactive CardioVascular and Thoracic Surgery 2013 Sep;17(3):467-71

Received: 03/07/2016

Accepted: 23/11/2016

Published: 20/12/2016

Disclosure and conflicts of interest:

Conflicts of interest were not reported.

\section{Corresponding author:}

Dr. Kıvanç Atılgan

Mail: kivancatilgan@gmail.com 